\title{
LA ORGANIZACIÓN RÍTMICA DE LA POESIA EN PROSA
}

Si bien -como repetidamente se ha dicho y analizado- la literatura es un tipo específico y diferenciado de discurso, los textos que conforman o ejemplifican el discurso poético -o literario - no son de la misma clase. Por una parte, aunque el predominio de la función poética de la lengua es indudable en todos ellos, las diversas culturas han realizado productos diferentes.

Todo texto verbal se produce mediante dos procedimientos básicos: la selección y la combinación. El texto literario, pues, se produce de la misma manera, pero con dos añadidos respecto de un texto referencial: 1) la selección se realiza no sólo a partir de una tradición lingüística y una situación ideológica, sino también a partir de una tradición literaria; y 2) las reglas de combinación posibles no son únicamente las gramaticales, de acuerdo con la norma lingüística del momento, sino además el repertorio de las reglas retóricas. La libertad de selección y combinación dentro de tan amplios repertorios está limitada, sin embargo, por un marco ideológico, en el sentido de que los procedimientos de producción de un texto deben adecuarse a la intención y a las posibilidades de comunicación de su contenido. De manera que -como señalan las Tesis de Praga de 1929-- pucde seguirse afirmando que un texto literario está determinado como único e insubstituible por una tradición lingüística, una tradición literaria y un marco ideológico.

Sin embargo, cada momento histórico cultural produce, a su vez, textos de diferentes clascs o, en otras palabras, textos de Ios que se han llamado diferentes "géneros". El problema de los géneros ha sido largamente discutido, y seguirá siéndolo mientras se pretenda establecer de una vez y para siempre los límites de cada género específico. Esto será imposible, a menos que se considere una y otra vez ese mismo problema 
sincrónicamente. Han surgido géneros nuevos en distintas épocas de acuerdo con distintas necesidades de comunicación. Pero todos ellos son también el resultado de un proceso de selección y combinación - con la salvedad de que en este caso se trata de recursos y no de signos-, que debe adecuarse a los requisitos del contenido.

Dentro de la cultura occidental, desde fines del siglo pasado se han producido unos textos denominados "poesía en prosa". Este nombre, si bien en un momento pudo parecer una contradicción, dado que la tradición había asignado el "verso" a la "poesía", tiene una razón de ser que considero interesante indagar. Planteada la hipótesis de que cada género diferente es producto de un proceso de selección y combinación de recursos, deben establecerse entonces tanto el "lexicón" de recursos con posibilidades de ser seleccionados, como el conjunto de reglas posibles de combinación. Sobre esta base puede indagarse la ausencia o presencia de ciertos recursos y su manejo particular en los textos considerados como "poemas en prosa".

El repertorio de recursos con posibilidad de ser utilizados en los textos literarios presenta dos tipos generales y distintos: los textuales, o sea los del texto en tanto que objeto y discurso, y los relatados, o sea los representados a través de la lengua; es decir los que en el análisis del relato se han llamado del discurso y de la historia, respectivamente. Así, los recursos del "lexicón" literario podrían ser los siguientes:

\section{Textuales (discurso):}

1.Espacio. Esto se refiere al espacio visual (vertical y horizontal) que ocupa el texto escrito sobre la página, o sea la extensión, la disposición tipográfica, y todos los blancos significativos que indican división y pausa (como por ejemplo, el verso, la estrofa, el párrafo, capítulos, partes, etc.).

2. Paralelismo fónico, o sea el de acentos y sonidos.

3. Paralelismo sintáctico, o sea el de categorías, funciones y estructuras de construcción.

4. Paralelismo léxico, es decir de significado entre más de un signo, considerando tanto signos simples (lexemas) como signos complejos (sintagmas). 
5. Enunciación interna; se refiere a la presencia o ausencia de antecedentes o referentes explícitos de los deícticos y anáforas dentro de lo relatado en el texto.

6. Tiempo. a) Se refiere al orden en que se presentan los acontecimientos relatados en el texto (cronológico, paralelos, invertido, por enclave); b) el aspecto morfológico, sintáctico y lexicológico con que se representa el tiempo relatado (concordancia u oposición).

Relatados (historia):

1. Acciones. Éstas pueden ser internas (evocadas, deseadas, imaginadas por los actantes) o externas (realizadas por los actantes en el transcurso del texto).

2. Actantes. Pueden ser personas, objetos o animales que lleven a cabo las acciones relatadas, así como el narrador o enunciador del texto (el "yo").

3. Tiempo. Puede ser interno o extemo ( $c f$. acciones)..

4. Espacio. Puede ser interno o externo ( $c f$. acciones).

Para establecer las reglas de combinación -la "gramática"- - de los recursos seleccionados es indispensable considerar, por una parte, que están determinadas por la función que cumple cada recurso dentro del texto $y$, por otra, que la combinación es siempre una manifestación simultánea y no sucesiva. Las distintas selecciones posibles se combinan en dos tipos básicos de organización rítmica, de acuerdo con las relaciones que se establecen. Éstos son:

1. EI ritmo semántico, que determina la aprehensión de uno o más significados mediante la presencia simultánea de las subestructuras rítmicas producidas por los paralelismos en los tres niveles básicos de la lengua, así como por la distancia que existe entre los recursos textuales y sus equivalentes relatados (por ejemplo entre el tiempo de la historia y el del discurso). Éste es un ritmo paradigmático.

2. El ritmo temático, o sea el desarrollo de lo relatado, del hilo narrativo, dado mediante una ordenación específica de segmentos namativos, su posible alternancia con segmentos no narrativos, y la cantidad de acontecimientos relatados. 
Éste es un ritmo sintagmático.

Tales organizaciones rítmicas delimitan cada género específico -en un momento determinado-- y responden, sin duda alguna, a una necesidad de comunicación; es decir, que el género como tal transmite por sí mismo una información complementaria a los significados del texto mismo.

Sobre estas premisas y la hipótesis planteada, intentaré derivar aquí, de manera general, la selección y la combinación (o sea la organización rítmica) que determinan lo que contemporáneamente se ha llamado "poesía en prosa", como género literario. A partir del repertorio descrito antes, este tipo de texto muestra un manejo particular de los seis recursos textuales de la siguiente manera:

1. Espacio: abarca todo el espacio horizontal, pero puede ser más breve -verticalmente- que el espacio de una página. Se compone de frases u oraciones (en general más de una), distribuidas en uno o más párrafos. Suele utilizarse la puntuación de manera convencional.

2. Paralelismo fónico: suele haber un ritmo acentual (en español) parecido al del "verso libre", sin rima ni metrificación regular. Es frecuente, sin embargo, el paralelismo fónico no final (no rimado) en figuras como la aliteración, la paronomasia, el políptoto, la similicadencia y la repetición léxica (identidad de palabras).

3. Paralelismo sintáctico: es muy frecuente y está muy marcado en todos sus aspectos.

4. Paralelismo léxico: está muy marcado, sobre todo por la brevedad del texto y la relación retórica entre enunciados.

5. Enunciación interna: suelen estar ausentes los antecedentes explícitos de los deícticos y anáforas del texto.

6. Tiempo: a) el orden, cuando hay un eje temporal explicito, suele ser cronológico; b) cuando hay tiempo relatado, las relaciones suelen ser retóricas.

Los recursos que he llamado relatados pueden a veces aparecer en un poema en prosa. Sin embargo, si aparecen se anulan posteriormente en tanto que recursos narrativos, para transformarse en tropos o partes de tropos. En otras palabras, los recursos textuales anulan siempre la narratividad (la historia), lo cual determina este tipo de texto como "poe- 
sía", independientemente de su forma externa. Así, pues, dada esta falta de narratividad, no puede hablarse de un ritmo temático en el pocma en prosa.

Aún sin haber entrado en detalles en este trabajo, puede. afirmarse que el poema en prosa se aproxima -más que a otros "géneros"- por un lado a la poesía en verso y por otro al cuento. Es interesante considerar que, si bien se distingue de uno por la falta de versificación (metro, rima, blancos) y del otro por la falta de narratividad, es sobre todo la organización la que los hace diferentes. Una breve descripción de estas otras clases de texto puede facilitar la descripción del ritmo semántico de la poesía en prosa.

El poema en verso -especialmente la llamada poesía líri$\mathrm{ca}-$, como el poema en prosa, no presenta una narratividad dominante, por lo cual tampoco tiene un ritmo temático, sino que desarrolla un ritmo semántico muy complejo. Apoyado en las subestructuras rítmicas -creadas por los paralelismos fónicos, sintácticos, léxicos y retóricos- cada signo del poema (palabra o sintagma), se encuentrá en relación de equivalencia con algún otro signo del texto. No hay elemento que quede excluido de alguna de estas subestructuras. Por lo tanto, el ritmo semántico se complica en una multiplicidad de isotopías - y de lecturas posibles-, lo cual provoca un movimiento constante de referencias cruzadas dentro del texto mismo, tanto paradigmáticas como sintagmáticas. La poesía en prosa presenta esta misma estructuración del ritmo semántico, pero se distinguc por la menor frecuencia y menor diversidad de los paralelismos fónicos y lo contrario respecto de los paralelismos sintácticos.

Por su parte, el cuento como género tiene una organización rítmica compuesta por una estructura fónica con pocas marcas, una estructura sintáctica bastante más marcada y una estructura de paralelismos léxicos (como Ia anáfora) muy frecuentes. Todo ello está en función de un hilo conductor de narratividad con un solo espacio relatado (continuo o no), un solo tiempo relatado (continuo o no) y pocos actantes. De tal manera que el ritmo semántico funciona como subordinado de una isotopía temática única y de un ritmo temático ascendente en intensidad y, en general, con el clímax al final. 
Todos los elementos del cuento existen en función de "un efecto único" (como decía Poe), pcro este género tiene como rasgo distinto del poema en prosa el hecho de que sus subestructuras rítmicas son más laxas. En otras palabras, los elementos del cuento pueden estar ligados sintáctica y temáticamente, y no es indispensable que pertenezcan a una o más de las subestructuras rítmicas. La poesía en prosa, entonces, básicamente repite en estructura el ritmo semántico del cuento, pero con relaciones paralelísticas más intensas, y no lo subordina a un ritmo temático.

Resumiendo un poco lo dicho hasta aquí, resulta que el ritmo semántico del poema en prosa -en tanto que es poesía - sc crea cn una red poliisotópica que se enriquece a medida que avanza cl texto, y en la que el final remite de alguna manera nuevamente al principio en una estructura cerrada única; o sea que manifiesta siempre los siguientes rasgos: 1) una subestructura sintáctica muy marcada, que cohesiona la red scmántica poliisolópica dada en la combinación de variantes e invariantes dentro de cada texto;2) una estructura ccrrada, formada por las diversas subestructuras rítmicas, en la que todos los signos del texto resultan integrados a más de una subestructura, además de las relaciones sintagmáticas; y 3) la anulación de la narratividad, en los textos que aparentan poseerla, mediante tropos que se integran en las subestructuras rítmicas.

Pero, adcmás de esto, había que intentar una determinación de la forma llamada prosa, para así ver en qué modifica específicamente el ritmo semántico del poema escrito en prosa. La prosa se distingue por cicrto tipo de relaciones sintagmáticas, notables sobre todo entre oraciones o unidades mayores. Me refiero a lo que Bally llamó "coordinación semántica" y que se produce básicamente por medio de deícticos, anafóricos y nexos de diversos tipos entre enunciados. La "coordinación semántica" entre enunciados suele darse en un orden lógico (causaiidad, disyunción, conjunción, exclusión, inclusión), en un orden temporal (sucesión de hechos). De tal manera, se crea un dinamismo sintagmático que impulsa Ia continuidad horizontal al agregar información en cada enunciado sucesivo, ya sea por desarrollo o por especifica- 
ción de elementos anteriores. Esto, a su vez, provoca un retorno al significado de la suma y síntesis de elementos precedentes integrados en una unidad, o sea un retorno al significado global del "universo del discurso", regido por una sola isotopía dominante, que puede llamarse "tema".

Así, pues, si se integra la función semántica de la forma textual llamada prosa a la caracterización anterior del poema, puede advertirse que la poesía en prosa, corno género específico y distinto, muestra siempre una tensión entre dos organizaciones rítmicas: el dinamismo paradigmático de la poesía y el dinamismo sintagmático de la prosa. En óras palabras, el texto presenta un ritmo temático inicial que se anula en alguna parte del texto, por lo cual se transforma el ritmo semántico de la siguiente manera: las relaciones sintagmáticas producen una integración de significados en una isotopía temática dominante que posteriormente se desintegra en varias isotopías simultáneas, mediante paralelismos lingüísticos que convierten las relaciones de coordinación semántica entre los enunciados sucesivos en relaciones paradigmáticas (o sea retóricas).

Es difícil en una ponencia, por su necesaria brevedad, ilustrar de una manera mínimamente convincente lo planteado como hipótesis. Sin embargo, intentaré por lo menos resumir algunos aspectos importantes para este propósito, que han resultado de análisis más detallados de ciertos textos. Para ello, ha parecido más conveniente èlegir poemas en prosa de un mismo autor, con el fin de mostrar el distinto uso de los mismos recursos seleccionados y sus distintas combinaciones en textos diferentes. Así pues, he elegido un conjunto de poemas en prosa, intitulado, La pedrada (1954) del poeta cubano Fayad Jamís.

\section{LA SERENIDAD DE LA SEMILLA}

La serenidad de la semilla cubierta de excremento, lanzada por los pájaros en el crepúsculo. Esa semilla ha cruzado los campos, ha cantado en las hojas carnosas del mazapán y de Ia muerte, $y$ ha sido vista por Pascual, el viejo nato y melancólico, en el fondo del río, donde una estrella de alba crece con raíces fragantes y cabcllera escamada. La serénidad en esa semilla de madre inmóvil, cu- 
bierta por ceniza, por abismo. Ella recuerda aquel estrépito, la ceiba, el zapateo. . . pero duerme: cierra los párpados en un viento que hiere los labios y huye con la última noche de tojosas y tataguas. La serenidad entre sus carnes débiles, allí donde una hebra amarillenta comienza a subir y respirar hacia el corazón de lo indecible.

Lo más evidente en la estructuración de este poema es que consta de cinco enunciados textuales en un solo párrafo (en este caso, llamaré así lo quẹ.se encuentra entre una mayúscula y un punto): tres frases nomirales y dos oraciones complejas, distribuidas de manera alternada. El núcleo de las nominales es "la serenidad" (de la semilla, en esa semilla, entre sus), mientras que el sujeto principal de las complejas es "la semilla" (esa semilla, ella). Por otra parte, llama la atención la alusión constante al espacio: inmovilidad (serenidad) y movimiento (semilla), así como la abundancia de verbos en las oraciones complejas. Las frases nominales expresan la inmovilidad de la semilla, por una parte, en la carencia de verbos, y por la otra mediante participios pasados ("cubierta de excremento", "lanzada por los pájaros", "cubierta por ceniza, por abismo") y complementos circunstanciales que, aunque son de distintos tipos, cumplen todos una función semántica de espacio e inmovilidad ("en el crepúsculo", "de madre inmóvil", "entre sus carnes débiles", "allí donde una hebra").

Por su parte, las oraciones complejas constan, la primera (o sea el enunciado textual 2) de dos oraciones simples (ha cruzado, ha cantado) y una compleja, de las cuales la última es pasiva (ha sido vista) e incluye una subordinada de lugar (donde crece); y la segunda (o sea el enunciado 4) consta de una oración compuesta adversativa (recuerda, pero duerme) y una compleja con subordinada compuesta copulativa (cierra, que hiere y que huye).

$\mathrm{Si}$ bien los verbos en sí, como categoría gramatical, en principio, indican acción y movimiento, resulta que el tiempo de conjugación, la transitividad y el significado léxico de cada uno de ellos los modifican. Los verbos cuyo sujeto real es la semilla tienen un significado léxico que indica inmovilidad, con la excepción de "ha cruzado" que por su conjugación (antepresente) indica un aspecto perfectivo. Los com- 
plementos circunstanciales de esos verbos son todos de lugar: "en las hojas", "en el fondo", "donde una estrella", "en un viento".

Hay en este poema paralelimos sintácticos muy marcados que apoyan, en todo, la característica de serenidad e inmovilidad de una semilla. Sin embargo, esto se complica tanto sintáctica como semánticamente en las tres oraciones subordinadas (incluidas en los enunciados textuales 2,4 y 5 ):

"/en el fondo del río / donde una estrella de alba crece con raíces fragantes y cabellera escamada" (2)

" cierra los párpados/en un viento que hiere los labios y huye con la última noche de tojosas y tataguas" (4)

"/entre sus carnes débiles, / allí donde una hebra amarillenta comienza a subir y respirar hacia el corazón de lo indecible" (5)

Estas tres tienen en común, además de su función sintáctica, una función semántica que es básicamente la de instaurar el movimiento dentro de la inmovilidad: los verbos, sobre todo "crece", "huye" y "comienza a subir", aunque sọn intransitivos indican la movilidad, tanto en el aspecto imperfectivo de su tiempo de conjugación como en su significado léxico incoativo. Sin embargo, hay que diferenciar las primeras dos (pertenecientes a los enunciados textuales 2 y 4) de la última (del enunciado 5), tanto por su construcción como por la posición que ocupan en el texto. Las primeras dos forman parte de las oraciones complejas interiores, mientras que la tercera forma parte de una frase nominal, es la última del poema. La subordinada del enunciado textual 2 tiene un verbo intransitivo en tiempo presente (crece), cuyo sujeto es "una estrella de alba" que -por relaciones que no pueden explicarse aquí- es sintáctica y semánticamente equivalente a la semilla, a su vez, sujeto principal del enunciado subordinante; por otra parte, el verbo (crece) está modificado sintácticamente por un complemento circunstancial de modo, pero que semánticamente modifica al sujeto (estrella de alba).

La subordinada del enunciado textual 4, por su parte, tiene dos verbos en presente del indicativo, de los que uno es tran- 
sitivo y el otro intransitivo, con el mismo sujeto "viento". Este sujeto es el úmico que léxicamentc implica movimiento y se relaciona en especial con "esa semilla ha cruzado los campos" del enunciado 2 y con "lanzada por los pájaros en el crepúsculo", modilicador del enunciado 1. El primer verbo de este sujeto (hierc) anula cl movimientō a pesar de su transitividad, al igual que cl objeto directo (los labios). Sin embargo, d) scgundo (huye) es equivalente a "crece" de la oración subordinada incluida en el enunciado 2 , entre otras cosas por su complemento circunstancial tambićn construido con la preposición "con", y también sintácticamente de modo; pero de la misma mánera, su función semántica no es de modificador del verbo sino del sujeto, como indicador temporal, relacionado con "en cl crepúsculo" del enunciado textual 1.

La tercera oración subordinada, parte del cnunciado $5 \mathrm{y}$ que cicrra el poema, tiene particularidades que la distinguen de todos los demás clementos del texto. Ante todo, el sujeto "una hebra amarillenta" es el único que no es equivalente ni a "serenidad" ni a "semilla" (ni metafórica, ni metonímica, ni sinecdóquicamente), sino que es consecuencia o resultado de la combinación de aquellos dos núcleos: serenidad y scmilla. Además, cl complemento circunstancial que modifica a los dos verbos,-lo cual los hace equivalentes- uno en lo scmántico y cl otro por posición y función gramatical, cs el único construido con una preposición indicadora de continuidad en el espacio (o sea de movimiento): "hacia". Por su parte, este complemento reune todos los aspectos de espacio y movimiento indicados en el texto, así como otros aspectos no analizados aquí, como por ejemplo la presencia de partes del cucrpo y de la oposición sonido/silencio: "hacia (indeterminado) el corazón (determinado) de lo indecible (indeterminado)".

Los aspectos señalados aquí intentan demostrar únicamente la importancia de la subestructura de paralelismos sintácti$\cos$ y su ocultamiento en la secuencia sintagnática, mediante los recursos de la coordinación semántica entre frases y oraciones (ver Anexo I). 
QUE TE COGE LA LLUVIA

iPártcle la madre al silencio y arrea tu caballo, que te coge la lluvia! El camino se empina sobre los farallones y el olor a sangre de almácigo. Si la lluvia te coge en el monte y el caballo se asusta Y resbala, ¿contra quć picdra irás a destriparte? ¿Quićn oiría tu grito desperdigado por las lomas, tu relincho incapaz de asustar a las guineas? iPártele la madre a la soledad y arrea tu alma hacia el viento, hacia cl humo, hacia el día!

En este poema sólo quisiera mostrar, independientemente de su estructuración y su organización rítmica, la presencia de elementos típicamente narrativos y su anulación posterior. Desde la primera palabra, un imperativo, se hace explícita la presencia de dos personas: el "yo" y el "tú". Este imperativo y el que le sigue como oración compuesta (arrea) se rcfieren a una acción que débe realizarse debido a una posible y probable consecuencia, explicitada en la creación causal yuxtapuesta (/por/que te coge la lluvia). Tal consecuencia, a su vez, se describe como negativa para el actante en la siguiente oración que se refiere al espacio que será recorrido por el "tú" (el camino se empina. .). Este rclato, que parece ser parte de un diálogo, continúa en la justificación de lo anterior con una crcación condicional subordinada a una interrogación, más otra interrogación donde aparece la no persona "quién"; en ćstas se refucrza temáticamente el pcligro de no llevar a cabo la primera acción recomendada por el "yo" en los imperativos que inician el texto. Hasta allí, han podido encontrarse actantes, acciones, tiempo y espacio que, en principio, son elementos narrativos y que determinan una unidad temática, o sea una isotopía dominante. Sin embargo, el último enunciado textual del poema anula toda la narratividad que parecía existir, en la transformación --dentro de la misma estructura sintáctica de base- del primer enunciado.

1. iPártele la madre al silencio

5. iPártele la madre a lá soledad

y arrea tu caballo y arrea tu alma 
1. que te coge la lluvia!

5. hacia el viento, hacia el humo, hacia el día!

Las primeras dos partes son idénticas con la excepción de un sustantivo en cada una (el objeto indirecto y el objeto directo). La lexía inicial de cada creación y sus objetivos indirectos funcionan de la misma manera: de primera instancia significan el deseo de destrüir el silencio y la soledad (que son equivalentes por semcjanza); sin cmbargo; "cl silencio" tiene muchos más apoyos léxicos (con concordancia sémica) en los enunciados intermedios, mientras que "la soledad" sólo sc apoya en "quién", sujeto de la interrogación anterior (cnunciado 4). Pero, además, están presentes un "yo" y un "tú" que contradicen la presencia de "la soledad", contradicción que se refuerza en que ésta se encuentra en la oración final del poema, mientras que "el silencio" está proyectado temporal y espacialmente mediante referencias explícitas al "camino". Las segundas partes tienen diferencias más complicadas, empezando por la concordancia sémica entre "arrea" y "caballo" y la falta de concordancia en la relación retórica cntrc "arrea" y "alma". Las terceras partes son totalmente diferentes: una cs una oración causal, mientras que la otra. consta de tres complementos circunstanciales de lugar equivalentes. La oración causal se relaciona con los imperativos anteriores tanto sintáctica como léxica y temáticamente, así como con la oración que le sigue (cl camino se empina ...). Por su parte, en el enunciado textual 5 , los núcleos de los complementos se relacionan con las oraciones precedentes sólo de manera retórica, pero al mismo tiempo pertenecen, según un criterio léxico simple, al paradigma temático (ambiente rural) de los primeros cuatro enunciados aparentemente narrativos: es decir, viento-humo-día, con caballo, lluvia, camino, farallones, almácigo, monte, piedra, Iomas, relincho, guineas. Las relaciones retóricas dentro de sintagmas particulares, que entre sí se relacionan en una continuidad narrativa, no anulan la narratividad. Pero en este caso, como suele suceder en la poesía en prosa, las relacioncs retóricas se dan entre un sintagmá y otro o entre enunciados, 
lo cual transforma en el momento de revelarse - que en este texto es al final- los significados establecidos anteriormente. Esto quiere decir que, si bien aquella isotopía temática permanece, por una parte se añade al menos otra isotopía, y además se anula la narratividad como hilo conductor y elemento unificador y dominante del texto. En este poema, por ejemplo, el sintagma "sangre de almácigo" dentro de la isotopía narrativa podría fácilmente traducirse por la resina o savia de ese árbol, y "tu relincho" como una sinécdoque metafórica de "tu caballo" y "tu grito". Sin embargo, la última oración del texto, y específicamente "arrea tu alma", transforma ambos sintagmas en tanto que signos complejos así como cada una de sus partes. Igualmente se transforman semánticamente los otros enunciados y sus segmentos, que aparentaban ser referenciales dentro de la isotopía narrativa. El texto se cierra sobre sí mismo dentro de su estructuración y se abre a múltiples significados: o sea que se convierte en un texto con el ritmo semántico característico de la poesía como tipo de discurso (ver Anexo II).

Considero que a través de estos ejemplos se han podido señalar brevemente algunos de los elementos típicos e incluso determinantes de la poesía en prosa, lo que permite definir estos textos como pertenecientes a una misma clase, es decir a un mismo "género" específico. En otras palabras, para responder a la pregunta de por qué un poeta a veces elige el verso y a veces la prosa para expresarse, se deberá recurrir a las distintas estructuraciones rítmicas y la información que transmiten como tales: el dinamismo paradigmático, el dinamismo sintagmático, o la combinación de ambos.

Me parece importante terminar estos planteamientos considerando la opinión de un poeta. Después de analizar algunos de sus textos - tanto en verso como en prosa- le pregunté a Fayad Jamís qué le hacía elegir una forma o la otra. La respuesta fue la siguiente: que escribía sus poemas en prosa cuando quería narrar algo o cuando quería decir algo como una "explicación". Independientemente de lo que he dicho acerca de la anulación de la narratividad en la poesía en prosa, la respuesta del poeta concuerda - aunque los términos 
sean distintos- con la función semántica de la prosa en un pocma. Es decir, que se comunica la poliisotopía mediante muchos recursos de la poesía en verso, pero se les añade el dinamismo sintagmático. Así pues, se comunica una unificación explícita de significados que después se desintegra en una multiplicidad simultánea.

Mónica MANSOUR

Pacultad de IFilosofía y Letras,

UNAM 


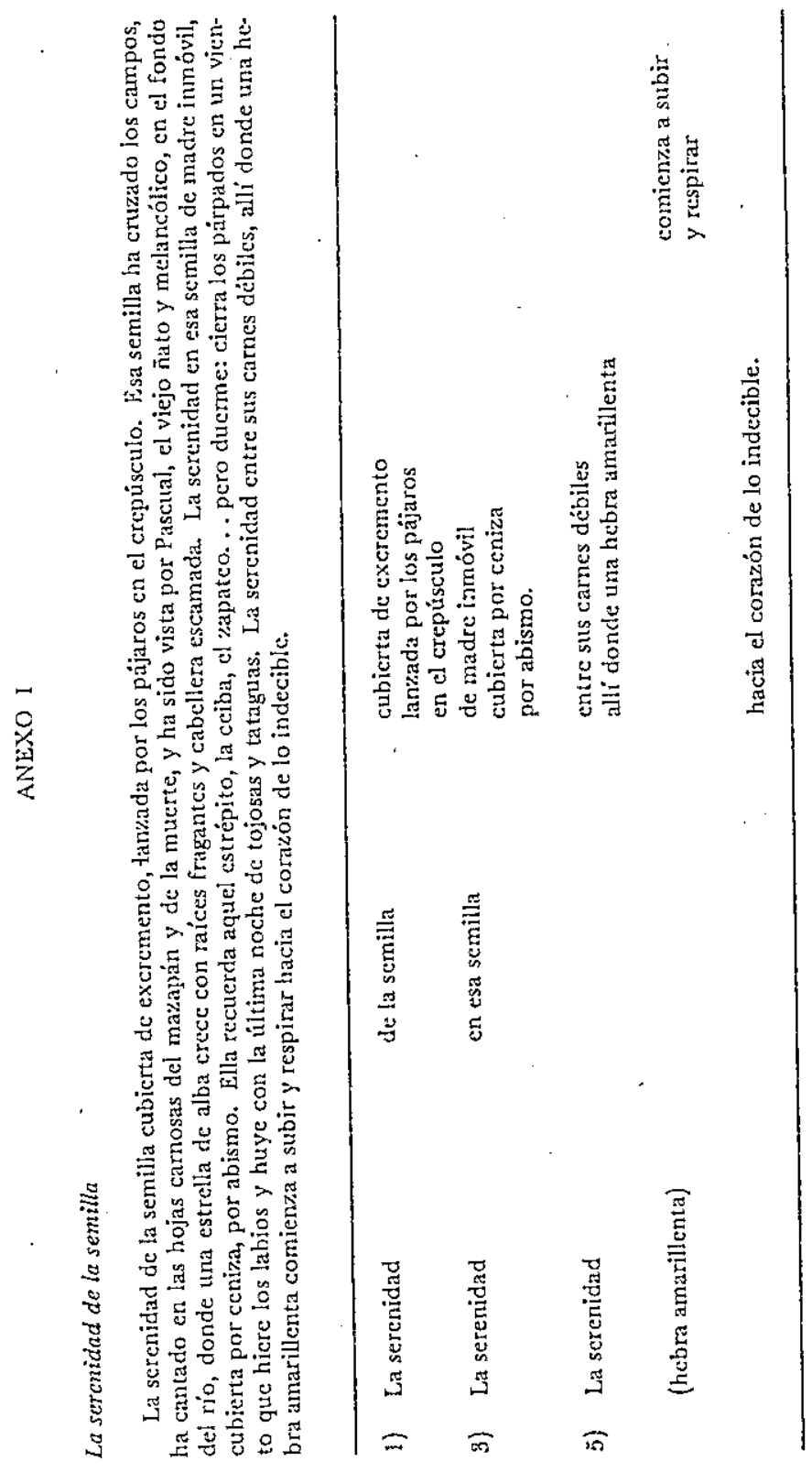



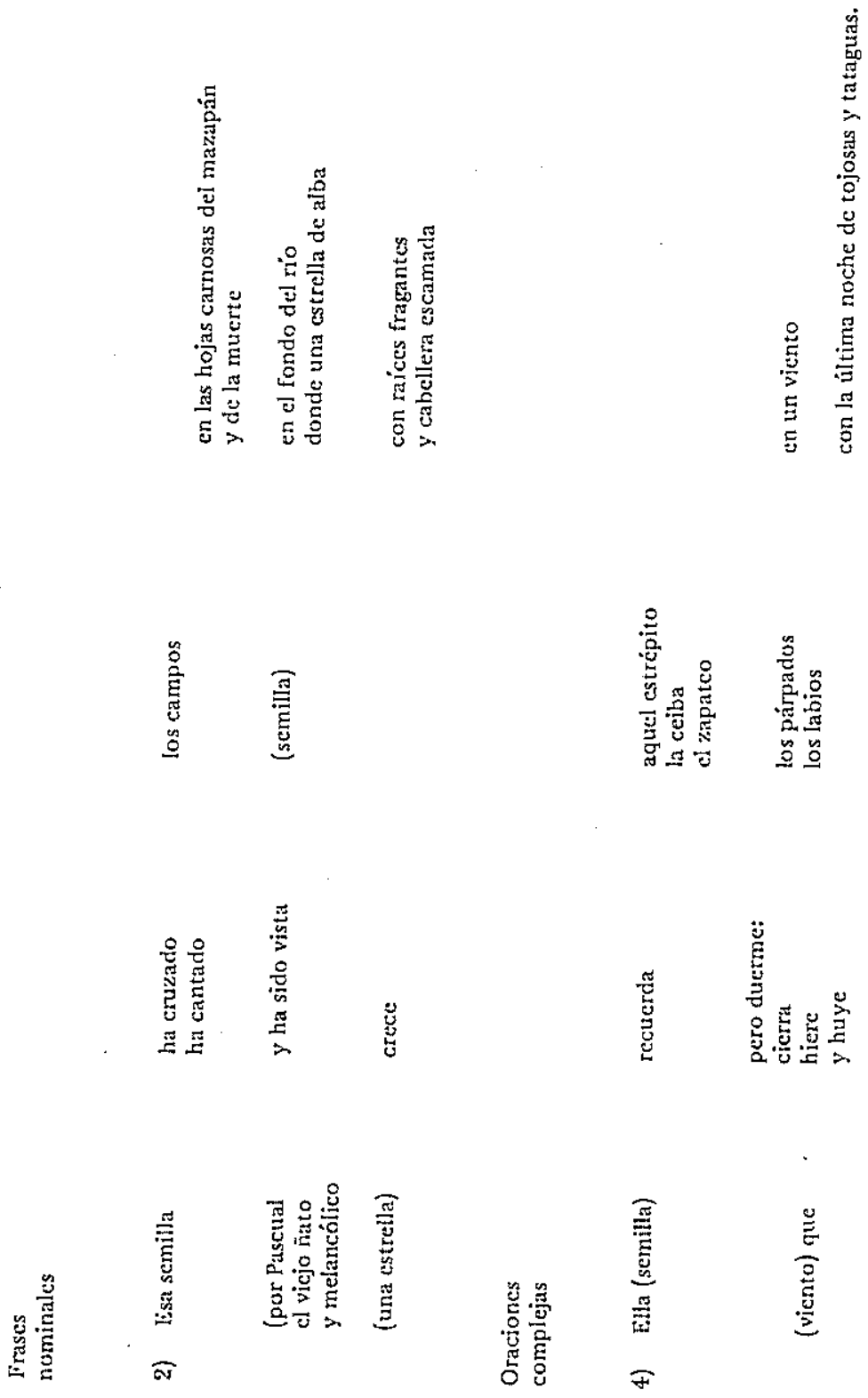
IA ORGANIZACIÓN RÍTMICA DE LA POESIA EN PROSA.

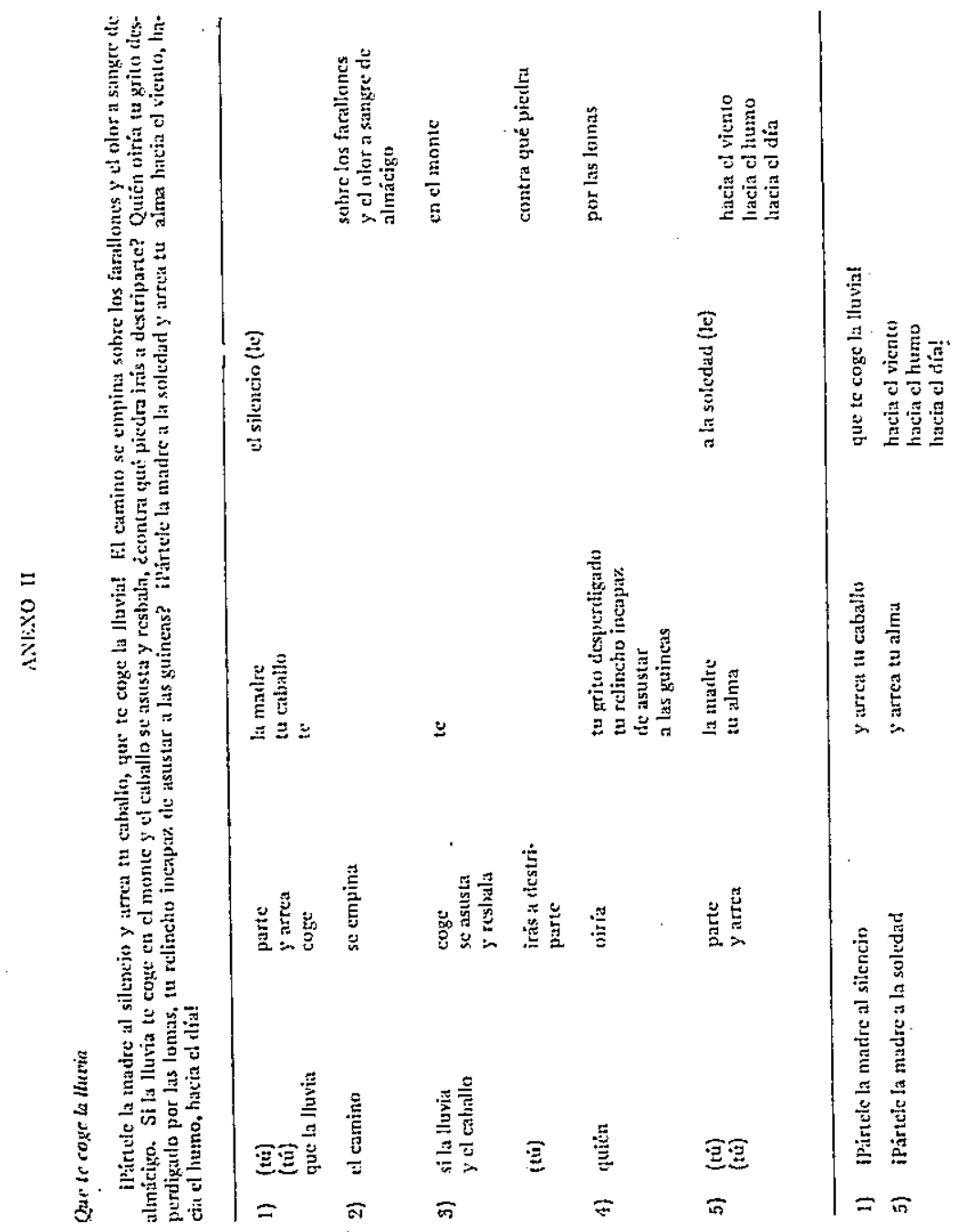

